\title{
An innovative concept for the technology of jelly-fruit marmalade using vegetable cryopastes
}

\author{
Maiia Artamonova ${ }^{1 *}$, Natalia Shmatchenko ${ }^{1}$, Tetyana Gavrysh ${ }^{2}$, and Liudmyla Pikh $^{2}$ \\ ${ }^{1}$ Department of technology of bread, confectionary, pasta and food concentrates, Kharkiv State University of Food Technology and \\ Trade, Kharkiv, Ukraine \\ ${ }^{2}$ Department of food technologies and processing industries, Kharkiv Petro Vasylenko National Technical University of Agriculture, \\ Kharkiv, Ukraine
}

\begin{abstract}
The results of research on the innovative concept of the technology of jelly-fruit marmalade with vegetable cryoadditives from carrots and pumpkin are presented. The use of innovative developments in marmalade makes it possible to increase productivity and improve the quality of products. It is shown that organoleptic, physicochemical quality indicators of marmalade with plant additives meet the requirements of current regulations, the colour intensity is maintained. The new products have an increased content of vitamin $C, \beta$-carotene and pectin.
\end{abstract}

\section{Introduction}

In modern economic conditions, food companies need to constantly improve existing products, production technologies, methods of their implementation, implement technical innovations, develop new products and bring them to market [1].

A sign of innovation is the requirement that the product, process, method, etc. must be new or significantly improved for the company. Innovations include products, processes or methods that the company first created. Another sign of innovation is that a product, process, marketing method or organization must be implemented. A new or improved product is introduced when it begins to be marketed [2].

Sugar confectionery due to the content of a large number of easily digestible sugars stimulates mental activity and provides energy to the human body. Also, the consumption of sugary confectionery promotes the body's production of the pleasure hormone - serotonin. However, today it is very difficult to choose confectionery without synthetic additives, because, unfortunately, modern confectionery production uses dyes and flavours, synthetic and identical to natural. Many of these supplements are not just harmful but dangerous.

One of the most common products containing synthetic additives are jelly products, so it is important today to create products using natural ingredients with high nutritional and biological value. The peculiarity of jelly products is their composition, which includes gelforming components: pectin, gelatine, agar-agar, as well as sugar-molasses syrup, fruit puree, fruit juices, sugar, molasses. Thanks to pectin, a soluble dietary fiber, marmalade is a useful food product.

The current state and prospects of improving the quality and nutritional value of jelly products by adding plant supplements are based on an analytical review of literature and patent sources [3-7]. To significantly reduce the risk of chronic diseases and meet the needs for micronutrients, daily consumption of fresh fruits and vegetables is recommended. However, fruits and vegetables have a very short shelf life due to their high moisture content. In addition, they have seasonal and regional availability, which limits the longer use of these products. To overcome these negative aspects, they are widely used to produce processed products such as jams, jellies and marmalades. [8].

It is established that the use of various additives of plant origin in marmalade technologies is one of the most promising technological methods to provide them with health and therapeutic properties, but in many cases the additives require additional mechanical or heat treatment, which leads to loss of biologically active substances. Therefore, today alternative methods of processing and storage of fruit and vegetables are processing by lowtemperature technologies.

Today in the food industry it is promising to use plant additives with increased amounts of biologically active substances obtained by modern technologies, such as cryogenic freezing and grinding $[9,10]$. Highly frozen vegetable supplements contain a significant amount of vitamins, carotenoids, pectin, which strengthen the immune system, as well as have a detoxifying effect on the human body. Grinding of raw materials as a technological technique is widely used in various branches of the food industry and largely ensures the quality of the finished product. In particular, as the particle size of the product decreases during grinding, its surface area increases. This allows more complete extraction of biologically active nutrients, aromatic substances with solvent, and also leads to increased 
digestibility of crushed products by the human body. The feasibility of using cryogenic grinding is closely related to the cost-effectiveness of the process. The cost of cooling is offset by the advantages of cryogenic technology, which for food products are determined by their quality, namely: the preservation of vitamins, aromatic and other biologically active substances (BAS), increasing the bioavailability and physiological efficiency of products. And this is equivalent to creating an additional amount of finished product of higher quality $[11,12]$. Therefore, to implement the innovative idea of the technology of jelly-fruit marmalade and increase its nutritional value, we have proposed the use of vegetable cryopastes from carrots and pumpkin.

\section{Experimental}

The aim of this work was to study the organoleptic and physicochemical properties of jelly-fruit marmalade on pectine with vegetable additives.

The object of research is organoleptic, physicochemical properties of the product. Subject of research - jelly-fruit marmalade on pectin with vegetable additives.

The resulting marmalade differed in the type of herbal supplement - cryopastes from pumpkin and carrots. Due to the low-temperature technology of their production, cryoadditives are a concentrate of biologically active substances, contain a significant amount of low- and high-molecular phenolic compounds, dietary fiber, vitamins, organic acids, macro- and microelements and have antioxidant, immunomodulatory properties and high colouring ability, taste and odour characteristics [11, 13].

Sampling for physicochemical studies of experimental samples was performed according to DSTU 4619: 2006. Determination of organoleptic characteristics of finished products was performed according to DSTU 4683: 2006.

The moisture content of the finished products was determined refractometrically according to DSTU 4910: 2008 , for this purpose a $50 \%$ solution was prepared: to a portion of $5 \mathrm{~g}$ of marmalade was added $5 \mathrm{ml}$ of distilled water and dissolved in a water bath to a homogeneous solution.

The titratable acidity of the finished products was determined according to DSTU 5024: 2008. To express the acidity in $\%$ of citric acid, the acidity in degrees was multiplied by the milliequivalent (0.07).

The mass fraction of vitamin $\mathrm{C}$ was determined using the titrometric method according to GOST 24556-89. The method is based on the redox reaction between ascorbic acid and the indicator 2,6-dichlorophenolindophenol (Tillmans reagent). The content of carotenoids was determined by colorimetric method according to GOST 13496.17-95. The method is based on the ability of carotene to dissolve in petroleum ether or gasoline, giving a yellow colour, the intensity of which is proportional to the carotene content. The content of pectic substances in plant raw materials and products of its processing was determined by one of the most accurate methods: calcium-pectate, which is based on the precipitation of pectic acids in the form of calcium salts. Determination of strength was performed on a penetrometer "Labor", recording the destructive weight.

\section{Results and discussion}

The Today, the main tasks of the food industry are: the creation of health products, new technologies for food production, recovery and use of food waste, ensuring the biosafety of packaging materials and more. Manufacturers are faced with the task of paying more attention to foods that meet the needs of consumers in a healthy lifestyle. As a result, there is a need to innovate in food technology and raw material processing, to withstand competition among manufacturers [14].

To create safe, high-quality, health-promoting products on the market, non-heat treatment technology is available. Innovative cryogenic food processing is often perceived as an alternative to heat treatment. The research conducted in the work pays attention to improving the functionality of food products due to the minimal processing of fresh vegetable raw materials, its quality, safety and ease of use. Of particular interest are studies on the "path to commercialization" for selected new technologies using plant additives obtained by cryotechnology [15].

The innovative strategy of this study provides:

-improvement of jelly-fruit marmalade technology with the use of vegetable cryopastes, which has certain competitive advantages over traditional technologies in this segment;

-offer products to expand the range of jelly products without the use of synthetic additives (flavours, essences, dyes);

-creation of new types of marmalade on pectin with high content of biologically active substances.

Taking into account the above information, a description of the innovative product was compiled (Table 1).

The use of innovative developments in the production of marmalade makes it possible to increase productivity and improve the quality of products.

The technological process for the production of jellyfruit marmalade contains the following stages: preparation of raw materials, preparation of the marmalade mass, the formation and gelation of the marmalade mass, removal of the marmalade from the molds and sprinkling with sugar, proofing (drying) of the marmalade, packing, packaging products.

To establish rational dosages of pumpkin and carrot cryopastes in marmalade technology, experimental samples with different numbers of cryopastes were made. Jelly-fruit marmalade on pectin with apple puree was chosen for control [16]. Cryopaste was used as a fruit additive in the samples studied and synthetic essences were completely excluded from the formulation. To do this, the marmalade mass was added thawed vegetable cryopaste at the end of the boiling stage in the amount of $5.0-25.0 \%$ of the total weight of the system. 
Table 1. An innovative concept of a new product - jelly-fruit marmalade with theuse of vegetable cryopastes

\begin{tabular}{|c|c|c|}
\hline Indicator & Characteristic & Sources of implementation \\
\hline $\begin{array}{c}\text { Product } \\
\text { appearance }\end{array}$ & $\begin{array}{c}\text { Fruit jelly marmalade has the correct form with a } \\
\text { clear drawing and accurate contours, without } \\
\text { deformation. The surface is evenly sprinkled with } \\
\text { white sugar }\end{array}$ & $\begin{array}{l}\text { Achieved by complying with the rational parameters of } \\
\text { the technological process and the use of gelling agents } \\
\text { and cryopastes }\end{array}$ \\
\hline Target segment & $\begin{array}{l}\text { The product is intended for consumption by the } \\
\text { general population }\end{array}$ & $\begin{array}{l}\text { B2C: general population through wholesale and retail } \\
\text { trade enterprises }\end{array}$ \\
\hline $\begin{array}{l}\text { Competitive } \\
\text { advantages }\end{array}$ & $\begin{array}{l}\text { Fruit jelly marmalade with vegetable cryopastes } \\
\text { and cryopowders is characterized by high content } \\
\text { of vitamin } C \text {, } \\
\text {-carotene, pectin and reducing the prescription } \\
\text { amount of the gelling agent }\end{array}$ & $\begin{array}{l}\text { Achieved through the implementation of technological } \\
\text { properties of plant cryoadditives }\end{array}$ \\
\hline Packaging & $\begin{array}{l}\text { Packing in paper-cardboard, polymeric and } \\
\text { polyethylene materials is provided }\end{array}$ & $\begin{array}{l}\text { Product weight from } 200 \mathrm{~g} \text { to } 7 \mathrm{~kg} \text { depending on the } \\
\text { form of sale }\end{array}$ \\
\hline Assortment & $\begin{array}{l}\text { The range of marmalade depends on the type of } \\
\text { cryopaste that is added }\end{array}$ & $\begin{array}{l}\text { The assortment is formed taking into account: } \\
\text { technological purpose, form of sale and demand }\end{array}$ \\
\hline Shelf life & 3 months & $\begin{array}{l}\text { Storage conditions for marmalade: in dry, clean, well- } \\
\text { ventilated warehouses at an air temperature of } 15 \text { to } 18^{\circ} \\
\mathrm{C} \text { and a relative humidity of no more than } 75 \%\end{array}$ \\
\hline $\begin{array}{c}\text { Estimated } \\
\text { wholesale price } \\
\text { per } 1 \mathrm{~kg}\end{array}$ & up to UAH 75 & $\begin{array}{l}\text { Achieved through the use of cryopastes and depends on } \\
\text { the cost of raw materials }\end{array}$ \\
\hline
\end{tabular}

The first step was to determine the strength of the obtained samples of marmalade with cryopastes for all dosages. The strength of the control sample was $(\tau 0=$ $12.5 \pm 0.63 \mathrm{kPa}$ ).

It is established that the addition of cryopastes increases the strength of marmalade, namely, with the introduction of cryopastes from carrots in the amount of $5.0-20.0 \%$, the strength increases by $8-34 \%$, from pumpkin - by $17-42 \%$. The increase in strength is due to a significant amount of pectin in plant cryopastes, so we can assume the possibility of reducing the amount of pectin according to the recipe. With a further increase in the prescription amount of cryopastes to $25 \%$, the strength index decreases and the structure of marmalade becomes viscous and brittle, which does not meet the requirements.

In the course of organoleptic studies, it was found that at dosages of cryopastes in the amount of 5.0-20.0\% of the total weight of the marmalade system has the correct shape, with a clear contour, without deformation, consistency - gel-like, not gummy. The taste and smell of the obtained products are pronounced due to the presence of cryopastes, without foreign taste and smell, but with an increase in the number of cryopastes there is a sour taste. Colour - from light orange to dark orange. When breaking the sample, the inner surfaces are transparent, without the inclusion of additives. The outer surface of the marmalade is evenly sprinkled with white sugar, elastic. In the case of adding cryopastes in the amount of $25.0 \%$ of the total weight of the system and above, the marmalade has a brittle not gel-like consistency, but more like jam, this is due to a violation of the pectin-sugar-acid balance.

Physico-chemical indicators of quality of samples of marmalade with a dosage of cryopastes in the amount of 5.0-20.0\% were studied

It is established that marmalade for all dosages meets the requirements of regulatory documentation [17] for physicochemical parameters (mass fraction of moisture in the range of $15.0-24.0 \%$; total acidity $7.5-22.5$ degrees; mass fraction of reducing substances is not more than $28.0 \%$ ). The acidity of the samples and the content of reducing substances in them increases according to the amount of additive. The strength index of marmalade when adding cryopastes increases compared to the control $(\tau 0=12.5 \pm 0.63 \mathrm{kPa})$ The strength of marmalade with the addition of cryopastes increases compared to the control by $8 \ldots .58 \%$, which gives grounds to reduce the prescription amount of gelling agent.

According to the results of studies of strength indicators with a decrease in the prescription amount of pectin by $5.0-25.0 \%$, it was found that it is advisable to reduce the prescription amount of pectin by $20.0 \%$ for all tested samples of marmalade. When reducing the amount of pectin by more than $20.0 \%$ of the prescribed amount, the strength of marmalade becomes lower than the control.

Thus, in the course of the research, the most rational dosages of cryopastes and pectin were selected, and formulations of new types of marmalade were developed:

-with carrot cryopaste in the amount of $10.0 \%$ of the total weight of the system with a reduced amount of gelling agent by $20.0 \%$;

-with pumpkin cryopaste in the amount of $10.0 \%$ of the total weight of the system with a reduced amount of gelling agent by $20.0 \%$;

-with carrot paste in the amount of $15.0 \%$ of the total weight of the system with a reduced amount of gelling agent by $20.0 \%$;

-with cryopaste from pumpkin in the amount of $15.0 \%$ of the total weight of the system with a reduced amount of gelling agent by $20.0 \%$;

Plant cryopastes contain a significant amount of biologically active substances, so it was important to determine the content of vitamin $\mathrm{C}, \beta$-carotene and pectin in new samples of marmalade (Table 2). 
Table 2. Content of vitamin c, $\beta$-carotin, and pectin substances in marmelad with addition of cryopastes

\begin{tabular}{|c|c|c|c|}
\hline \multirow[t]{2}{*}{ Marmalade } & \multicolumn{3}{|c|}{ Content of biologically active substances } \\
\hline & $\begin{array}{l}\text { Vitamin C, } \\
\mathrm{mg} / 100 \mathrm{~g}\end{array}$ & $\begin{array}{l}\beta \text {-carotene, } \\
\mathrm{mg} / 100 \mathrm{~g}\end{array}$ & $\begin{array}{c}\text { Pectin } \\
\text { substances, } \\
\mathrm{mg} / 100 \mathrm{~g}\end{array}$ \\
\hline $\begin{array}{l}\text { according to } \\
\text { the } \\
\text { traditional } \\
\text { formulation }\end{array}$ & $0.40 \pm 0.02$ & trace & $1.55 \pm 0.08$ \\
\hline \multicolumn{4}{|c|}{$\begin{array}{l}\text { with carrot cryopaste in quantity (from the total weight of the } \\
\text { system): }\end{array}$} \\
\hline $10.0 \%$ & $0.56 \pm 0.03$ & $3.50 \pm 0.18$ & $1.50 \pm 0.08$ \\
\hline $15.0 \%$ & $0,90 \pm 0.03$ & $5.10 \pm 0.26$ & $3.45 \pm 0.18$ \\
\hline \multicolumn{4}{|c|}{$\begin{array}{l}\text { with pumpkin cryopaste in quantity (from the total weight of } \\
\text { the system): }\end{array}$} \\
\hline $10.0 \%$ & $1.20 \pm 0.06$ & $3.00 \pm 0.15$ & $2.70 \pm 0.14$ \\
\hline $15.0 \%$ & $1,80 \pm 0.09$ & $4.50 \pm 0.23$ & $3.90 \pm 0.20$ \\
\hline
\end{tabular}

As can be seen from the table, the content of vitamin $\mathrm{C}$ in marmalade with the addition of vegetable cryopastes in the amount of 10.0 and $15.0 \%$ increases approximately 1.4-4.5 times according to the type and number of cryopastes compared to the control. The control sample of marmalade does not contain $\beta$-carotene, and $100 \mathrm{~g}$ of marmalade with cryopaste from carrots and pumpkin in the amount of $10.0-15.0 \%$ contains $3.1-5.0 \mathrm{mg} / 100 \mathrm{~g}$ of $\beta$-carotene depending on the type and number of cryopastes. The content of pectin substances in marmalade with the introduction of fruit and vegetable cryopastes increases up to 2.5 times.

Based on the physiological needs of a person, the daily amount of vitamin $\mathrm{C}$ is $75 \mathrm{mg}$, carotene - $5 \mathrm{mg}$, pectin substances - $5 \mathrm{~g}$, and anthocyanin substances - 80 $\mathrm{mg}$. To provide marmalade with the status of a product of health-improving action, the content of these physiologically functional ingredients should be $20-50 \%$ of the daily requirement of a person $[16,17]$. Therefore, it is important to calculate the content of these biologically active substances in relation to the average daily human need for $100 \mathrm{~g}$ of new products (Table 3). Data are given in $\%$ in relation to the average daily requirement of an adult.

The table shows that the content of $\beta$-carotene in marmalade with the addition of cryopaste from carrots and pumpkin in the amount of $10-15 \%$ is $60.0-102.0 \%$ of the average daily human need. The content of pectin substances in new samples of marmalade is $30.0-78.0 \%$ of the average daily human need. Therefore, these samples can be considered products of health effects.

\section{Conclusion}

An innovative idea to expand the range of jelly-fruit marmalade with increased nutritional value was identified. Formulations and technologies of marmalade with the addition of vegetable cryopastes have been developed. The use of cryopastes made from carrots and pumpkin has reduced the prescription amount of pectin by $20 \%$. Organoleptic and physicochemical parameters of new products meet the requirements of current regulations. The resulting marmalade products have a high content of vitamin $C, \beta$-carotene and pectin. Based on the results of research on new products, draft regulatory documents in the form of technical conditions and technological instructions were developed, the safety of technology was assessed using the HACCP system.

Table 3. Content of vitamin c, $\beta$-carotin and pectin substances in marmalade with addition of cryopastes in relation to the average daily need of adults

\begin{tabular}{|c|c|c|c|}
\hline \multirow[t]{2}{*}{ Marmalade } & \multicolumn{3}{|c|}{$\begin{array}{l}\text { The content of substances relative to the } \\
\text { average daily requirement when consuming } \\
100 \mathrm{~g} \text { of marmalade, } \%\end{array}$} \\
\hline & Vitamin C & $\beta$-carotene & $\begin{array}{c}\text { Pectin } \\
\text { substances }\end{array}$ \\
\hline $\begin{array}{l}\text { According to } \\
\text { the } \\
\text { traditional } \\
\text { formulation }\end{array}$ & 0.5 & - & 31.0 \\
\hline \multicolumn{4}{|c|}{$\begin{array}{l}\text { with carrot cryopaste in quantity (from the total weight of } \\
\text { the system): }\end{array}$} \\
\hline $10.0 \%$ & 0.6 & 70.0 & 30.0 \\
\hline $15.0 \%$ & 1.2 & 102.0 & 69.0 \\
\hline \multicolumn{4}{|c|}{$\begin{array}{l}\text { with pumpkin cryopaste in quantity (from the total weight of } \\
\text { the system): }\end{array}$} \\
\hline $10.0 \%$ & 1.6 & 60.0 & 54.0 \\
\hline $15.0 \%$ & 2.4 & 90.0 & 78.0 \\
\hline
\end{tabular}

\section{References}

1. N. Skopenko, Herald of Lviv Polytechnic National University, 684, 66-71(2010)

2. N. Chorna, Innovative development of food production and food security risks ( monograph, Lviv, 2012)

3. A. Bashta, T. Leshchynska, Scientific Works of NUFT, 53, 63-70 (2013)

4. N. Sanzharovskaia, O. Khrapko, "Technical sciences, 64, 95-98 (2017)

5. N. Ershova, N. Tarasenko, "Composition for the production of marmalade," Patent RF, no. 2650549, (2018)

6. G. Tsyibikova, S. Batumunkeeva, 'Vegetable marmalade," Patent RF, no. 2631307, (2017)

7. Magomedov G. O., Method for producing jelly marmalade using concentrated pumpkin paste. Patent RF, no. 2603895 (2016).

8. T. Swer, S. Rani, Kh. Bashir, Processing of Fruits and Vegetables From Farm to Fork,366 (2019)

9. I. Syazin, G. Kasyanov, Food technology, 4, 123124 (2012)

10. M. Ahmedov, G. Kasyanov, A. Ramazanov, Z. Yaralieva, "Innovative technologies for the production of fruit and vegetable cryopowders," Abstract journal "Food and processing industry", No. 3, pp. 135-149

11. R. Pavlyuk, V. Pogarskaya, V. Pavlyuk, A. Berestova, N. Maksimova, Cryomechanochemistry in food nanotechnology, monograph, (2015)

12. R. Pavliuk, "New about carotenoids and oxidative enzymes of carotenoid vegetables during cryogenic "shock" freezing and grinding," Advanced 
techniques and technologies of food production, restaurant business and trade, No. 1, pp. 52-60

13. V. Poharska, "Study of cryomechanical destruction and mechanochemistry processes in the development of nanotechnology of frozen carotenoid plant additives," Eastern-European Journal of Enterprise Technologies, 84, pp. 39-46, 2016)

14. Ch. Galanakis, "Innovation Strategies in the Food Industry," 1st ed., Academic Press, (2016)
15. O. Tokusoglu, "Introduction to Innovative Food Processing and Technology," Natural Science and Discovery, 4, pp. 85-87, (2015)

16. L. Kuznetsova, M. Sidanova, Production of marmalade-pastille products, Moscow: DeLi plus, (2012)

17. State Standart 4333-2004, Marmalade. General technical conditions, Kyiv, The State Committee of Ukraine for Technical regulation and Consumer policy, (2004) 